\title{
Thomas Bernhard'ın Auslöschung (Yok Etme) romanındaki fotoğraflarda medyalararasılık olgusu
}

\section{Sami TÜRK1}

\begin{abstract}
APA: Türk, M. S. (2020). Thomas Bernhard'ın Auslöschung (Yok Etme) romanındaki fotoğraflarda medyalararasılık olgusu. RumeliDE Dil ve Edebiyat Araştırmaları Dergisi, (20), 509-515. DOI: 10.2900o/rumelide.792107.
\end{abstract}

\section{Öz}

Medyalararasılık kavramına günümüzde özellikle edebiyat biliminde sıklıkla rastlanmaktadır. Birçok farklı yerde ve farklı amaç için kullanılmakla beraber ancak Rajewsky'nin net bir kalıba oturtmasıyla açıklığa kavuşan terimin edebiyatta birçok yansımasını görmek mümkündür. Bu çalışma da; medyalararasılığın Rajewsky'nin kavramlaştırdığı haline dayanarak Avusturyalı yazar Thomas Bernhard'ın ölümünden iki sene önce yayımlanan, geç dönem eserlerinden ve oldukça hacimli olan Auslöschung. Ein Zerfall romanında anlatıcının geçmişini ve düşüncelerini aktarmasını sevk eden bir unsur olduğu tespitinden hareketle romanda kısa kısa tasvir edilen fotoğrafların romana medyalararasılık özelliği kattığı iddiasını öne sürmektedir. 1931-1989 yılları arasında yaşayan Bernhard'ın girift bir dili ve alışılagelmişin dışında bir anlatım tarzı vardır. Bu çalışmada, Türkiye'de de ciddi bir okur kitlesine sahip olan yazarın Yok Etme başlı̆̆ıyla tercüme edilen eserin içeriği, yazar hakkında verilen kısa biyografik bilgilerden sonra anahatlarıyla aktarılmakta, akabinde medyalararasılık kavramının tanımına geçilmektedir. Bu minvalde önce terimin barındırdığı medya kelimesinin anlamına temas edilmekte, sonrasında McLuhan'ın açıklamalarına yer verilmekte ve medyalararasılık kavramının tanımı ile detaylarına geçilmektedir. Medyalararasılık genel olarak üç farklı şekilde görülebilmektedir. Bunlar; İki veya daha çok medyanın varlıklarını sürdürerek beraber bulundukları opera, film gibi medya kombinasyonları, bir medyadaki konu veya olayların başka bir medyaya aktarılması sonucu esas alınan medyanın varlığını kaybederek başka bir medyayla değiştirildiği, sözgelimi edebiyat eserlerinin film uyarlamaları gibi medya değişmeleri, son olarak da aynı medya içerisinde iki veya daha çok medyanın etkileşime girdiği medyalararası ilişkilerdir. Makalede, roman işte bu üçüncü tezahür şekli üzerinden incelenmektedir.

Anahtar kelimeler: Medyalararasılık, Thomas Bernhard, Yok Etme, fotoğraf

\section{Intermediality based on the photos in Thomas Bernhards Novel Extinction}

\begin{abstract}
The term intermediality is often used today in literary studies. It is also used in various fields for various purposes, but it was only with the definition of Rajewsky that it became clear and provided the basis for numerous literary analyzes. This article also makes use of it and asserts that the sparsely described photos in the comprehensive novel Extinction by the Austrian writer Thomas Bernhard encourage the narrator to relate his thoughts and past and that these photos turn this novel into an intermedial work. Bernhard, who was born in 1931 and died in 1989, had a complicated style and an unusual way of narrating. This work gives brief biographical information about the writer, who is also admired by a large audience in Turkey, and also about the content of the work. It takes the next step with the definition of intermediality. In this context, the word "medium" is first described, then McLuhan's definition of it and intermediality are defined and explained in more detail. Intermediality
\end{abstract}

1 Öğr. Gör. Sakarya Üniversitesi, Fen Edebiyat Fakültesi, Alman Dili ve Edebiyatı Bölümü (Sakarya, Türkiye), mturk@sakarya.edu.tr, ORCID ID: 00oo-0003-2350-5901 [Makale kaylt tarihi: 28.08.2020-kabul tarihi: 20.09.2020; DOI: $10.29000 /$ rumelide.792107] 
can appear in three different ways. First, as a media combination, where at least two media are present together, such as in operas or films. Second, as a media change, where topics or actions in one medium are transferred to another medium, e.g. in literary adaptations. And thirdly, intermedial references in which at least two media interact. The present article analyzes the novel Extinction in the context of these very intermedial references.

Keywords: Intermediality, Thomas Bernhard, Extinction, photography

\section{Giriş}

Bu makalede Thomas Bernhard'ın Türkçe'ye Yok Etme başlığıyla çevrilen Auslöschung romanındaki² medyalararasılık olgusu incelenecektir, çünkü bu makaleyi yazarken romanda kısaca bahsi geçen üç fotoğrafın anlatıyı kurucu ve ilerletici bir görev üstlendikleri, dolayısıyla edebiyat medyasıyla kurdukları ilişki üzerinden onunla bir etkileşimde bulundukları varsayımından hareket edilmektedir. İnceleme öncesinde ilkin yazarın kısaca kim olduğundan bahsedilecek ve romanın içeriği kabaca tasvir edilecektir. Bir sonraki safhada, -özellikle Türkiye'deki- edebiyatbilimi araştırmalarında yenice bir metot olduğu söylenebilecek medyalararasılık kavramına temas edilerek kavramın kapsamı ve uygulama sahası açıklanacaktır. Bu sırada kavram, genel çerçevede, bir medya içerisinde belirli bir fonksiyon üstlenmek kaydıyla başka bir medyanın da kullanıma sokulmasıyla en az iki medyanın beraber kullanılması şeklinde anlaşlarak oluşum tarihi içerisinde tanımlanacak, son olarak da araştırma nesnesi romanın incelenmesine geçilecek, içindeki medyalararası unsurlar ortaya konacaktır.

\section{Yazara dair}

Thomas Bernhard 9 Şubat 1931 tarihinde, annesi Herta Bernhard'ın hizmetçilikle geçindiği Hollanda'nın Heerlen şehrinde gayrimeşru bir çocuk olarak dünyaya gelmiştir. Babası, marangozlukla uğraşan Alois Zuckerstätter'dir. Doğumunun ertesi yılı Viyana'daki büyükannesi ile büyükbabasının yanında yaşamaya başlamış, 1940 yılında, intihar teşebbüsü neticesi olduğu tahmin edilen bir gaz zehirlenmesinden ölen öz babasıyla hiç tanışmamıştır.

Babasının ölümünü takip eden yıl, başka biriyle evlenen annesiyle yaşadığı problemlerden ötürü Thüringen eyaletinin Saalfeld şehrinde bulunan bir nasyonalsosyalist eğitim yurduna gönderilmiştir. Bundan bahsedilmesinin sebebi, oradayken hayatının geri kalanında bir daha kurtulamayacağı travmatik tecrübeler geçirmiş olmasıdır. Esasen ailesine, sosyal işlerden sorumlu bir devlet memuresince, küçük Bernhard'ın istirahat edebileceği Salzburg'daki Saalfelden şehri tavsiye edilmiş fakat aile orayı Almanya'daki şehirle karıştırmıştır. Bu tesadüf veya talihsizlik hayatını şekillendiren başlıca olaylardan sayılması hasebiyle ayrıca dikkate değerdir. 1943 yılına gelindiğinde nasyonalsosyalistlerin Salzburg'daki Johanneum yatılı okuluna yerleştirilmiştir. Büyükbabası geçim sıkıntısı çekmelerine rağmen Bernhard'ın eğitimine olabildiğince katkıda bulunmaya çalışmışsa da Bernhard üç yıl sonra okul hayatını terk etmiş, okul kurumunu sonraları "zihin yok etme müessesesi" (Bernhard, 1998: 82) diye tarif etmiştir. 1947'de ise bir gıda tüccarının yanında çıraklık eğitimine başlamıştır.

1949 Ocak ayı itibariyle ağır bir tüberküloza yakalanması sonucu defalarca sanatoryumda kalmış, bu hastalığın şahsiyetinde bıraktığı izler de hemen her eserine yansımıştır. 1988 yılının kasım ayında kaptığı akciğer enfeksiyonunda bakımını, zaten on yıldır tedavisiyle ilgilenen dâhiliye hastalıkları uzmanı üvey kardeşi üstlenmiştir. 12 Şubat 1989'da ise evindeyken kalp sektesinden hayatını kaybetmiştir.

\footnotetext{
2 Romandan yapılan alıntılar Almanca aslından alınacak olup çevirileri makalenin yazarına aittir. Adres Address 


\section{Romanın içeriği}

Burada incelemeye alınacak Auslöschung romanında ben-anlatıcı konumunda bulunan Franz-Josef Murau, henüz hikâyenin başında, ebeveyni ile erkek kardeşi Johannes’in ölümünü bildiren bir telgraf alır fakat ölüm sebepleri yazılmamıştır. Pek fazla olayın anlatılmadığı hikâyede anlatıcı, dinleyicisi veya muhatabı diyebileceğimiz öğrencisi Gambetti’ye hitaben geriye dönerek geçmişiyle alakalı manzaralar ve ailevi yaşantısına dair detaylar sunar. Tüm bunları anlatırken hareket noktasını hep eski günlerinden geriye kalan üç fotoğraf teşkil etmektedir.

Geleneksel anlatı formlarından ciddi sapmalar göstermekle beraber Bernhard'ın diğer anlatılarından aşina gelen ve 651 sayfa uzunluğuyla son derece hacimli olan eserde baştan itibaren toplam iki paragraf bulunmakta, bu paragraf başları birer bölüm niteliği taşımaktadır. İlk bölüm anlatının başkişisinin ailesine dair bir tasvir sunarken ikinci bölümde cenaze merasimi münasebetiyle ailenin nesillerdir mülkiyetinde bulunan, Wolfsegg'deki köşküne dönüş ve cenazenin detayları aktarılmaktadır. Anlatı sırasında, Bernhard, tanıdık üslubuyla, abartma tekniğine çokça başvurarak siyasetten dine, oradan da sosyal şartlara dek hayatın hemen her alanını çetin bir eleştiriye tâbi tutmaktadır. Romanın başlığı olan "yok etme", anlatıcının; çarpık bir eğitimden geçtiğini iddia ettiği çocukluğunu, gençliğini, Katoliklik ile nasyonalsoyalizmin doğurduğu yıkıcı sonuçları ve sonuç olarak aile mülkünün bulunduğu Wolfsegg'den bahsedilince tasavvur ettiği her şeyi hatıralarını kaleme almak suretiyle yok etme niyetine dayanmaktadır.

\section{Medyalararasılık nedir?}

Medyalararasılık kavramını açıklamadan önce medyanın ne olduğunu tanımlamak yerinde olacaktır. Bunun için önce sözlük anlamına bakmakta fayda vardır. Medya sözlükte, "Radyo, televizyon, gazete, dergi vb. iletişim ve yayın organlarının tamâmına verilen ad” (Ayverdi, 2016: 786) diye geçmekte, böylelikle aslında bir taraftan günlük dildeki kullanılışının sınırlılığı ortaya çıkmaktadır. Nitekim günlük dilde medyadan anlaşılan, çoğunlukla; radyo, televizyon veya gazete gibi yazıll, sözlü ve görülü organlardan ibaret kalmaktadır. Oysa Latince'den kök alan kelimenin etimolojisine bakıldığında, "orta" anlamı taşıdığı görülmekte, sözgelimi Almanca'da da en geniş anlamıyla "aktarıcı/aracı [ortadaki] unsur” (Wermke, 2007: 655) karşllı̆̆ına rastlanmaktadır. Öyleyse kelimenin ilkin Türkçe’deki dar anlamından sıyrılarak daha geniş bir zaviyeden anlaşılması gerekliliği doğar ki terim anlamı da yerli yerine oturabilsin. Bu bakımdan biz medyayı öncelikle araç diye anlamaktan tarafız.

Terim anlamına gelince; kavramın bu denli yaygınlaşmasını sağlayan kişi, 1964'te yayımladığı Understanding Media: The Extensions of Man isimli çalışmasıyla Kanadalı filozof Marshall McLuhan olmuştur. Onun tanımıyla medya en geniş anlamında mesajdır. Bu mesajdan maksat da her tür medyanın "öz kişiliğimizin her türden uzantısı" (McLuhan, 1994: 7) olması keyfiyetidir. Böylelikle her medyanın şahsi ve sosyal etkilerinin öz kişiliğimizin uzantıları veya yeni yeni teknolojiler yoluyla hayatımıza giren yeni ölçütlerden ortaya çıktığı kastedilmektedir. Yine McLuhan’ın verdiği bir örnekle biraz daha açmak gerekirse, sözgelimi elektrik lambası kendi başına bir bilgidir ama mesajı olmayan bir medyadır, mesajının olması için mesela harf harf bir reklam metnini yansıtması gerekir ki buradan her medyanın karakteristik özelliği olarak medya içeriklerinin de başlı başına birer medya olduğu sonucu çıkarılabilecektir. Nitekim yazının içeriği dil, matbaanın içeriği yazılan kelime, telgrafın içeriği ise baskıdır. (1994: 8) Böyle bakıldığında medya -bilhassa Türkçe'de yaşadığı anlam daralmasının hilafına- çok daha genel bir çerçeveye oturmakta, anlamı son derece genişlemektedir. Dolayısıyla insanların birarada yaşayışlarının kapsamını belirleyip biçimini veren ve aynı zamanda da yönlendiren unsur halini almaktadır. 
Elbette bir edebiyat metnini incelerken kullanacağımız medyalararasılık kavramı böylesi bir anlam genişliğinden beslenirken öbür taraftan da özel bir inceleme metodu olması bakımından kendine has bir biçime kavuşturulmaktadır. Özellikle 90'lı yıllarda sıklıkla kullanılmaya başlanan bir kavram olan medyalararasılığın tıpkı geçmişte linguistic turn'den bahsedildiği gibi zamanımızda da "intermedial turn" ifadesiyle adeta geniş çaplı bir yönelime ismini verecek denli yaygınlaştığını söyleyen Rajewsky, kavramın yaşadığı bu popülerliğe rağmen "açık seçik tanımlanmamış" olduğunu kaydederek 2002'de yayımladığı Intermedialität (Medyalararasılık) kitabında tam da bu işe, yani "herkesin ağzında dolaşmasına" rağmen netlik kazanmamış kavramı tanımlamaya teşebbüs etmiştir (2002: 1-3). Bu makalede de incelemeye konu roman ele alınırken aynı tanıma müracaat edilecektir. Fakat öncesinde ilk ortaya çıkışı ve tarihî gelişimine göz atmanın faydası olacaktır.

Pekgöz ve Keleş’in bildirdiğine göre kavrama ilkin 1812 tarihinde İngiliz şair Samuel Taylor Coleridge'de “intermedium” şeklinde rastlanmaktadır. Almanca'da ilk bilimsel kullanımı ise Hansen-Löve'nin 1983 tarihli bir yayınında geçmektedir. Medyalararasılık karşılı̆̆ını ilk önerip kullanan Ersel Kayaoğlu olmuş, 2006 yılında yayımladığı bir makalesinde de ilk kez bir metin çözümlemesi içerisinde kullanmıştır. Onur Bilge Kula ise medyalararasılık yerine "araçlar arasılık / ara-araçlı" çevirilerini önerse de medyalararasılık karşılığının oldukça yerleştiği göze çarpmaktadır ve bu makalede de öyle kullanılacaktır. (2020: 182)

Kavramın ortaya çıkış ve gelişim safhalarına ilişkin bu girişten sonra Rajewsky'nin tanımına geçilebilir. Buna göre medyalararasılık en geniş ifadesiyle, "geleneksel olarak apayrı algılanan en az iki medyayı içeren ve medyaların sınırlarını aşan tezahürler[dir]” (2002: 13). Yani sözgelimi çalışmamız özelinde örneklendirecek olursak edebiyat ve film, edebiyat ve resim/fotoğraf veya edebiyat ve müzik gibi aslında birbirinden farklı yerlere konan medyaların birbirlerini içermesi anlamına gelmektedir. Akla ilkin metinlerarasılığı getiriyor ve onunla karıştırılma ihtimali barındırıyor olsa da, bu konu hakkında Türkiye'de ilk çalışmaları yapanlardan Kayaoğlu medyalararasılığın onu aşan bir kavram olduğunu belirtir, "çünkü medyalararasılık olgusunda her şeyden önce, farklı medyalara has içerik ve sunuş biçimlerinin birbirine bağlanması söz konusudur” (2012: 106). Öyleyse kastedilen, herhangi iki medyanın rastgele birarada bulunuşu değil, -en az- iki farklı medyanın fonksiyonel olarak kullanılması, birinin diğeri içinde belli bir iş görmesi, yani etkileşime girmeleridir. Metinlerarasıllk ise salt metinlerin birbiriyle ilişkisi ve etkileşimini tazammun ettiğinden tek başına medyalararasılık gibi bir olguyu kapsamakta yetersiz kalacaktır. Nitekim Kayaoğlu da bu yetersizlikten bahisle farklı sanat dallarını birer metin sayarak metnin anlamını genişletmenin metinlerin anlamına odaklanmakla yetinmek sonucunu doğuracağını ve mevcut sanat eserindeki medyaların kendi fonksiyonlarının dikkatten kaçmış olacağını ifade etmektedir. (2009: 53-54) Öte yandan Rajewsky'nin; edebiyat metni olsun, film olsun, hatta bir tablo olsun, kendisinden tamamen ayrı algılanan yabancı bir medyada üretilmiş bir esere veya yabancı bir medyanın göstergeler sistemine, söylem biçimlerine atıfta bulunması yahut onları taklit etmesini medyalararasılı̆̆ın varlığına işaret sayması özellikle bir sonraki altbölümümüzde yapacağımız roman analizi bakımından önem arz etmektedir.

Medyalararasılıkla ilgili kaydedilmesi gereken son husus, bu olgunun tam olarak ne şekillerde ortaya çıktığından söz etmek olacaktır. Rajewsky'den hareketle medyalararasılı̆̆ın üç tezahür şeklinden bahsetmek mümkündür. Bunlardan ilki "medyaların kombinasyonudur" ki opera veya film gibi iki ayrı medyayı tek bünyede buluşturup etkileşime sokan eserlerdir. İkincisi "medyaların değiştirilmesidir" ve kastedilen mesela bir konunun edebiyat medyasında bir romanda işlenirken daha sonra filme aktarılması olabilir, edebiyat eserlerinin filmleştirilmesi sırasında yazılı medyadan görme-işitmeli medyaya geçilerek kaynak alınan medya bizzat ortadan kalkmaktadır. Üçüncüsüneyse "medyalararası ilişkiler" demekte ve "edebiyat metinleri, film veya tabloların belirli başka bir medya ürünüyle ilişkisi" (2002: 16-17) diye tarif etmektedir, burada gerçekleşen, birbirinden ayrı olarak algılanan bir medyanın kendine has araçlarla konu edilmesi, taklide uğraması veya yeniden üretilmesidir, şu farkla ki medya 
değişimindeki gibi bir medya ortadan kalkıp diğeri devreye girmemekte, her iki medya da, daha doğrusu diğerinin içine katılan medya da varlığını korumaktadır. Medyanın sözlük ve terim anlamıla beraber medyalararasılık kavramını da tanımladıktan sonra aşağıda Auslöschung romanının medyalararasılıkla analizine yer verilecektir.

\section{Romanın çözümlenmesi}

Yukarıda romanın içeriğinden kısaca bahsederken anlatı boyunca üç farklı fotoğrafın anıldığı belirtilmişti. Romanın ben-anlatıcısı Murau ilk kısım boyunca özellikle ilk iki fotoğrafa bakmaktadır. Fotoğrafların birinde ebeveyni, diğerindeyse kardeşi mevcuttur, böylelikle romanın aynı zamanda benanlatıcısı da olan başkişi geçmişle ilişki kurmaktadır. Bu anlamda denebilir ki fotoğraflar olup bitenlerin anlatılmasını tetikleme vazifesi görmekte, hafızanın hatıra arşivini karıştırmaktadır. Nitekim SchmitzEmans'a göre fotoğraf ile arşiv arasındaki fonksiyon ilişkisi fotoğraf ile hafızanın çağrışımlarla birbirine bağlanmasını sağlayan zemini kurmaktadır (2009: 303). Roman için neden yok etme anlamına gelen bir isim seçildiğini belirtirken yukarıda da gördüğümüz üzere anlatıcı aile mülkünün bulunduğu Wolfsegg'le alakalı ne varsa silmeye, yok etmeye çalışmaktadır. Bu amaç muvacehesinde bakıldığında anlatıda yer verilen fotoğraflar "unutma medyası olarak" (a.g.e.) yeni bir perspektif kazanmaktadır.

Fotoğrafların fonksiyonları arasında canlandırmak, yeniden can vermek de vardır, tevekkeli "Günter Anders fotoğraflarda -canlı asılları reprodüksiyonlarla ikame etmek anlamında- dünyanın hayaletleştirilmesine destek çıkan bir medya" (a.g.e.) görmektedir. Bu bakımdan görülü bir medya olan fotoğraf görülü hale getirme fonksiyonuna sahip olmakla geçmiş ve hâlihazır arasında aracılıkta bulunurken "görünmeze görünürlük" (a.g.e.: 308) bahşetmektedir. Bu anlamda geçmişten maksat henüz sağken çekildikleri fotoğrafların içeriklerini oluşturan ebeveyn ile erkek kardeş olurken, hâlihazır, fotoğraflara ve fotoğraflara bakan anlatıcıya işaret etmektedir. Görülmektedir ki aile fotoğraflarının varlığı anlatıyı tahrik kuvvetine sahip bir iş görmektedir.

Fotoğrafların bir yandan ölümün habercisi olarak tasvir edilip diğer yandan ölümlülüğe karşı koyuş olarak görüldükleri, dolayısıyla bir çift-anlamlılık barındırdıkları varsayımından yola çıkılırsa fotoğraflar durduğu müddetçe (müteveffa) aile fertleri nereye gitse takip edecekleri için Murau'nun tüm hatıraları yok etme niyetiyle bu varsayım arasında bir çelişki ortaya çıktığı da düşünebilir. Bu düşüncede doğrudan bir haklılık payı mevcuttur, çelişkinin nasıl çözüldüğünden makalenin sonunda bahsedilecektir.

Fotoğraflar romanın başkişisinin anlatma faaliyetini teşvikle kalmayıp düşüncelerini dile getirmesine de zemin hazırlamaktadırlar. Bu bakımdan fotoğraf "tabiatın tahrifinden" (Bernhard, 1988: 21) başka bir anlama gelmemektedir, çünkü insanları asıl hallerinde göstermeyip groteskleştirmektedir. Metnin yine bir başka yerinde, Bernhard'ın üslubuyla alakalı yukarıda da bahsettiğimiz abartı tekniğine başvurusu açısından fotoğrafın "yirminci yüzyılın en büyük felaketi” (a.g.e.: 30) olduğu da dile getirilmektedir.

Buraya kadar ailenin yalnızca ölen fertlerinden hareket edip fotoğrafları geçmişle bağ kurmanın aracı, geçmişe götüren bir medya olarak yorumladıysak da üçüncü fotoğrafta hâlen hayatta olan iki kız kardeşi görülmektedir. Ama kız kardeşlerinden de en az öbürküler kadar nefret eder. Çünkü onlar da "hayalet gibidirler, güya canlıdırlar, nefret edilesidirler” (a.g.e.: 316). Ailenin ölü fertlerinin resmedildiği ilk iki fotoğrafın aksine üçüncü fotoğrafa ilk bakışında fotoğrafta bulunan kişileri anlatmaz; amcası Georg'un fotoğrafın arkaplanında duran ve kız kardeşlerinden daha canlıymış gibi görünen villası onu amcası hakkında konuşmaya iter. 
Hayatı boyunca hiç fotoğraf makinesi almamış bulunan Murau'nun ebeveyni ile erkek kardeşinin fotoğrafını çektiği birkaç istisna hariç asla ne fotoğraf çekmesi ne de saklaması, hatta fotoğraflardan kelimenin tam anlamıyla tiksiniyor olması gerçeği ilginç bir durumdur, çünkü ebeveyni ile erkek kardeşinin fotoğraflarını bu tiksintisine rağmen çekmiş olmasının, "geriye bakıldığında bir cinayet ritüeli [ânı] olduğu anlaşılmaktadır. Aile fertlerini fotoğrafla öldürmesi onları 'yok etme'sine işaret etmektedir. Bu çıkarımı tek tutarlı gösteren, anlatıcının aile fertlerinin fotoğrafını sadece bir defa çekmiş olmasıdır, çünkü adam öldürmek de ancak bir kez mümkün olmaktadır" (Schmitz-Emans, 2009: 317). Murau'nun annesinin biraz uzunca görünen boynunun dikkatini çektiği fotoğrafa bakışında da (Bernhard, 1988: 24) telgrafta saklanan ölüm sebebinin sezdirildiği çok açıtır, çünkü annesi ölürken kafası kopmuştur.

Murau'nun hatıralarını anlatması veya kaleme alması onları yok etmek için tek başına yeterli gelmeyecektir. Fotoğrafların bir yandan ölümün habercisi olup diğer yandan ölümlülüğe karşı koyuş şeklinde beliren yukarıda da zikrettiğimiz çelişkisi ancak bizzat fotoğrafların da yok edilmesiyle ortadan kaldırılabilecektir. "Öyleyse burada -resimler dolayısıyla hem somut hem mecazi anlamılaperformatif bir dil edimi söz konusudur.” (Schmitz-Emans, 2009: 317)

\section{Sonuç}

Yazar hakkında kısa bir bilgi verdikten sonra eserin de kaba bir taslağını aktararak başladığımız makalede medyalararasılık kavramını medyanın sözlük ve terim anlamları üzerinden Rajewsky'nin tanımıyla açıklayıp üç tezahür şeklinden bahsetmiştik. Bunlar medyaların kombinasyonu, medyaların değiştirilmesi ve medyalararası ilişkilerdi. Bir sonraki aşamada eseri medyalararasılık bakımından incelediğimizde fotoğrafların herhangi bir medya olarak kullanılmayıp romanın başkişi Murau'nun geçmişini ve düşüncelerini anlatmasını sağlayan bir motor unsur vazifesi görmesi, ayrıca peşini bırakmayan mazisi ve ailesiyle hem sözlü hem edimli olarak bağını koparabilmesini sağlamak gibi önemli fonksiyonlar icra etmeleri bakımından salt zikredilmenin ötesinde anlatı faaliyetiyle etkileşim kurduklarını görmüş olduk.

Anlatı faaliyetinin bir parçası haline gelen fotoğraf medyası, hikâyenin akışına yaptığı katkı düşünüldüğünde barındırdığı çift yönlü anlamlar vasıtasıyla romanın anlatı biçimine doğrudan katkıda bulunmaktadır. Burada edebiyat medyasının yanısıra ikinci medya olarak fotoğraf medyasının ihtiva ettiği alt sistemlerin ve anlatım biçiminin, anlatının içinde üstlendiği rol; okur, yazar ve dolayısıyla metin bağlamında oldukça önemlidir, zira bu ikinci medyanın anlatı imkânlarının da bu eksende hikâyenin bir parçası olması medyalararasılığın merkez noktasını oluşturduğu iddia edilebilecek medyalar arası ilişkiler meselesine oldukça uygun bir örnektir. Dolayısıyla Thomas Bernhard'ın Auslöschung romanını, edebiyat medyası içerisinde fotoğraf medyasının, kendine has aktarım ve sunum özelliklerini yitirmeksizin kullanılarak her iki medyanın etkileşime girdiği, medyalararası ilişkiler kullanan bir roman olarak sınıflandırmak mümkündür.

\section{Kaynakça}

Ayverdi, İ. (2016), Misalli Büyük Türkçe Sözlük, İstanbul: Kubbealtı Neşriyat.

Bernhard, T. (1988), Auslöschung. Ein Zerfall, Frankfurt am Main: Suhrkamp.

Bernhard, T. (1998), Die Ursache. Eine Andeutung. Salzburg und Wien: Residenz Verlag.

Kayaoğlu, E. (2012), Intermediales Erzaehlen in Evelyn Grills Roman Vanitas oder Hofstaetters Begierden, Studien zur deutschen Sprache und Literatur, o (18).

Kayaoğlu, E. (2009), Medyalararasılık. Edebiyat Biliminde Yeni Bir Yaklaşım, İstanbul: Selenge.

McLuhan, M. (1994), Understandig Media - The Extensions of Man, Cambrigde, Massachusets, London: The MIT Press. 
Pekgöz, E; Keleş, A (2020), Oğuz Atay’nn Tehlikeli Oyunlar Romanı ile Poyraz Karayel Dizisinin Medyalararasılık Bağlamında Karşılaştırılması, Iğdır Üniversitesi Sos Bil Der Sayı / No. 22, Nisan /: 175-202.

Rajewsky, Irina (2002), Intermedialität, Stuttgart: UTB.

Schmitz-Emans, M. (2009): Gespenster. Metaphern der Photographie in der Literatur, A. Simonis içinde, Intermedialität und Kulturaustausch. Beobachtungen im Spannungsfeld von Künsten und Medien, Bielefeld: transcript-Verl. (Kultur- und Medientheorie).

Wermke, M. (2007), Duden - Das Fremdwörterbuch, Mannheim: Bibliographisches Institut GmbH. 